This is an electronic reprint of the original article. This reprint may differ from the original in pagination and typographic detail.

Author(s): Taipale, Sakari

Title: Synchronicity matters: defining the characteristics of digital generations

Year: $\quad 2016$

Version:

Please cite the original version:

Taipale, S. (2016). Synchronicity matters: defining the characteristics of digital generations. Information, Communication \& Society, 19(1), 80-94. https://doi.org/10.1080/1369118X.2015.1093528

All material supplied via JYX is protected by copyright and other intellectual property rights, and duplication or sale of all or part of any of the repository collections is not permitted, except that material may be duplicated by you for your research use or educational purposes in electronic or print form. You must obtain permission for any other use. Electronic or print copies may not be offered, whether for sale or otherwise to anyone who is not an authorised user. 


\section{Synchronicity Matters: Defining the Characteristics of Digital Generations}

\section{Sakari Taipale}

Department of Social Sciences and Philosophy, University of Jyvaskyla, Jyvaskyla, Finland

P.O. Box 35, Ylistonmaentie 33, 40014, Jyvaskyla, Finland, sakari.taipale@jyu.fi, +358

400728852

Dr Sakari Taipale is an Adjunct Professor and an Academy of Finland Research Fellow at the University of Jyväskylä, Finland. In 2015, he holds the position of Visiting Professor at the University of Udine, Italy. Currently, he is leading a project on Intergenerational Relations in Broadband Societies (2013-2018), funded by the Academy of Finland. His research works have been published in journals such as the British Journal of Sociology, New Media and Society, Mobilities, and Social Science Research.

Word count: 7,123

Acknowledgement: This work was supported by the Academy of Finland under Grant 265986 


\section{Synchronicity Matters: Defining the Characteristics of Digital Generations}

This article investigates whether or not the proposition that the second digital generation (or so-called digital natives) is more engaged in social use of the Internet than older generations is tenable. By analysing nationally representative questionnaire based survey data collected from Finland in $2011(\mathrm{~N}=612)$, the study shows that rather than social use of the Internet in general, it is the synchronicity of online communication that distinguishes user generations. Results show that, in contrast to asynchronous modes of online communication (e.g. social networking sites, blogs, online discussion forums), synchronous modes (e.g. instant messaging and Internet calls) are clearly generationally differentiated practices. They are more frequently used by the second digital generation than the first digital generation (1DG) and digital immigrants (DI). Furthermore, the study shows that asynchronous uses of the Internet are clearly gendered in nature. Women are more typically users of social networking sites and blogs than men, whereas men are more often engaged with discussion forums than women. These results are discussed in light of two concepts: privacy and communicative efficacy. The studied forms of synchronous online communication provide more privacy as well as an instant and abundant channel for effective communication, which are all features especially appreciated by the youngest user generation.

Keywords: digital generations, Internet, social media, synchronicity, communication 


\section{Introduction}

Many efforts have already been made to identify social generations that would differ from the preceding ones with regard to the use of digital media (Dingli \& Seychell, 2015; Montgomery, 2007; Prensky, 2001a; Tapscott, 1998). In most cases the distinguishing factor has been higher engagement in the most recent information and communication technology (ICT). Nevertheless, the youngest generations, born into and grown up in a world that is thoroughly mediated by technology, are often far too easily considered as innately technology savvy and active users of digital media. From Prensky’s initiative (2001a, 2001b), these generations have been widely called 'digital natives' to differentiate them from 'digital immigrants’ (DI), who were born earlier (before the 1980s) and only adopted digital technologies at a later age. Such stark juxtapositions of the two generations have been subsequently questioned by more detailed empirical investigations (e.g., Davies, Coleman, \& Livingstone, 2014; Hargittai, 2010; Helsper, 2010; Helsper \& Eynon, 2010; Lee, 2008). The notion of digital natives is said to reflect the distorted view of parents and others, who tend to mystify the mundane sides of digital media. Like any other skill, digital media skills must be learnt and socialized into, and hence some scholars would like to put aside the generation terminology (e.g. boyd, 2014; Hargittai, 2010). Later, Prensky (2009) himself noticed that his original distinction had become less relevant as digital technologies evolved so rapidly. He suggests that more and more attention should be paid to prudent use of the new technology and to the wisdom arising from the use of digital technologies.

In fact, empirical studies have also provided support for these critics, showing that digital natives and immigrants do not comprise coherent and clearly defined social groups as regards ICT use. For example, Hargittai (2010) shows how race/ethnicity, the number of years of using the Internet and the weekly hours of web use affect online skills, and how these skills, along with the time spent on the web each week, increase the diversity of Internet 
use, contributing to stratification among the networked (young) people. Similarly, Lee (2008) has shown that Internet access and usage have remained by and large concentrated in wealthier households in the UK, contradicting the idea of young people as techno-enthusiasts and experts regardless of their background. Helsper (2010), in turn, presents that life stage could be a more powerful predictor in this respect than generation. The natives vs. immigrants division makes us overrate the difference between generations and overlook the diversity within them. Herring (2008) has argued that these so-called natives are actually a kind of 'transitional generation', as they are still using both analogue and digital media. As such, they can also work as intermediaries between the digital immigrants and the new digital generations who are increasingly unfamiliar with both the old analogue media and the older forms of digital media.

More recently, Helsper and Eynon (2010) jointly suggested that the social functionalities of the Internet (e.g. Facebook, MySpace) may have created a second generation of digital natives. Helsper and Eynon maintain that the second generation would differ from the first generations of natives, born in the 1980s, in its greater familiarity and immersion in Web 2.0, which refers to the developmental phase that makes the Internet more social and participatory in nature (Fuchs, 2010, for more detailed analysis and criticism). In 2015, Dingli and Seychell put forward an idea that people born towards the end of the first decade of the twenty-first century could be called 'the new digital natives'. This new generation is able to deal with wireless technologies and touch screen at once when infant and toddler, while the previous generation of digital natives came in contact with digital technologies relatively late, only when they learnt to control a mouse and to read. All in all, these many parallel and at least partially competing attempts to define the new generations of digital technology users imply how vigorous, yet also elusive, a sociological category the generation is when trying to unpack the social diversities of digital societies. 
In this study, the terms the first and the second digital generation (1DG and 2DG respectively) are used to simplify this tangle of concepts and conceptualizations (see also, Fortunati, Taipale, \& de Luca, forthcoming). 1DG refers to people born in the 1980s who were exposed to and gained hands-on experience of the first digital technologies at a relatively early stage of their life. 2DG is considered as a generation that was born in the 1990s or later and who, following the suggestion of Helsper and Eynon (2010), should be more engaged with the social functions of the Internet. Digital immigrants (DI) will also be tackled in the analysis. They will serve as a point of reference in order to understand the particularities of the two digital generations.

Based on these definitions and considerations, the aim of this article is defined as being to empirically test if 2DG is really different from 1DG in Finland, in terms of its closer engagement with the social functions of the Internet. In their study, Helsper and Eynon (2010, p. 510) used bivariate methods to show that there are statistically significant differences in Internet uses between various age groups in general. However, their analysis does not reveal if the difference between the first and second digital generations (or natives) in particular is statistically significant. While using multivariate methods, Helsper and Eynon (2010, pp. 512-514) applied respondents' age as a continuous variable in their models. In so doing, their study is not able to reveal whether or not there are differences between specific age groups/cohorts, or so-called societal generations (Pilcher, 1994), and if any possible differences are statistically significant.

To overcome these limitations, this study will exploit both bivariate methods and a logistic regression analysis. The social uses of the Internet will be measured with five dependent variables, which are used disjointedly to paint a more nuanced picture of the studied phenomenon. The separate use of these five measures allows detection of whether the social uses of the Internet are differently related to generations. On the other hand, the 
strength of logistic regression analysis in this connection is that it makes possible the testing of whether the differences between specific generations, with relation to the social uses of the Internet, are statistically significant. The analysis will be carried out with a nationally representative questionnaire data $(\mathrm{N}=612)$ collected from Finland during May-June 2011.

The rest of the paper is structured in the following way. The paper begins with a discussion of the development of the Internet from an information sharing network to a platform of social interaction and cooperation, as well as how this development is related to the rise of new user generations. At the same time, previous empirical literature and statistics are reviewed to lay a solid basis for research hypotheses. The data, measurement instruments and statistical procedures are described before moving on to a results section. The paper will end with discussion and concluding remarks.

\section{Co-evolution of the Internet and user generations}

Living through and learning to use similar functions of the Internet is a binding factor amongst people who belong to the same societal generation of Internet users. Fuchs (2008, pp. 125-136) presents that the first phase of Internet development, the so-called Web 1.0, was a tool for thought. Internet usage was chiefly characterized by the idea that everybody is able to publish information online and engage him/herself in the global web. 1DG was born before the world where Web 1.0 was taking its first steps, while digital immigrants had grown up for many decades without any digital technologies and encountered them only at a later phase of their lives. With the rise of new interactive and social platforms, such as MySpace, YouTube, Twitter and Facebook, the Internet became a channel of communication and was labelled Web 2.0. According to Fuchs (2008, p. 126), this change truly took place around 2005. Web 3.0 is seen to come about along with new platforms such as Wikipedia and GoogleDocs, which require cooperative and real-time efforts from users. It is increasingly based on synchronous forms of communication, such as instant messaging, chatting and video 
conferencing, which complement the older social functions of the Internet that were more intermittent by nature. It is especially these social functionalities of Web 2.0, and the cooperative and relative communicative uses of the Web 3.0, that can be seen as peculiar to the 2DG born in the 1990s or later.

These recent improvements in Internet technology have aimed to make communication and electronically mediated sociability smoother and effortless. Many of these new features have also added to the instantaneous of communication and information exchange, enabling real-time collaboration. Wellman, Quan Haase, Witte and Hampton (2001) already discovered in 2001 by using an exploratory factor analysis that Internet uses can be divided into synchronous and asynchronous activities. Synchronous activities necessitate that at least two people are simultaneously involved in an activity. By contrast, asynchronous use does not require simultaneous availability of both parties. At that time, Wellman et al. could not find demographic characteristics that would be strongly related to any synchronous online activity, only that respondents with a university degree were more likely to be users of synchronous Internet activities in their study, analysis of which was based on a sample of US and Canadian citizens. The authors assumed that the reason for weak and no associations was the wide penetration and use of the Internet in the given countries. It is worth noting that at that time the 2DG was still very young, and hence was not included in their sample.

Considering this parallel development of Internet technology (from asynchronous to increasingly synchronous) and user generations (from late age adopters to infants and toddlers embedded in the digital world), it makes sense to approach the social uses of the Internet by dividing them into synchronous and asynchronous modes of communication. Given the limited number of relevant measurements in the used data, the following five modalities of the social use of the Internet will be analysed more carefully in this paper. 
Instant messaging and Internet telephone calls represent the synchronous modes of communication, and the use of social networking sites, blogs and online discussion forms are addressed as the examples of asynchronous use.

Synchronous modes of communication include instant messaging (IM) that, according to Baron (2008), became a widespread phenomenon in the US in the late 1990s. Baron maintains that it was at the turn of twenty-first century that 'America's teenagers and college students shifted their computer allegiances (if they had any yet) from email to IM’ (Baron, 2008, p. 45). This means that the growth of IM took place at a time when 2DGs were only at the age where they began to use digital communication technologies. Baron also shows the gendered nature of IM: women are more "talkative" than men. Unsurprisingly, the use of IM services is much more popular among younger generations than older ones. Statistics Finland (2014), which collects information only about the use of IM services via a mobile phone (e.g. WhatsApp), reports that 88 per cent of 16-24 year-olds had used these services within the last three months, and 75 per cent of them on a daily basis in 2014 . The rates of IM service use decline rapidly towards older age cohorts. Of 55-64 year-olds, only 13 per cent have used these services with the last three months. The other synchronous mode of communication investigated here is the use of Internet telephony. As a mode of communication, it is even more novel than IM; yet, as a medium of oral communication, it supplements the mobile phone and the fixed telephone. Previous results show that cost effectiveness is one of the main motivators for the adoption and use of Internet telephony (Constantiou \& Kautz, 2008; Park, 2010). Research work from Denmark and the UK indicates that the youngest users are perhaps not the most active users of Internet telephony, which accounts, at least partially, for the common and more regular use of Internet telephone calls for professional purposes (Cecere \& Corrocher, 2011; Constantiou \& Kautz, 2008). Besides employees, studies show that housewives could be more active users of Internet 
telephony than other social groups (Cecere \& Corrocher, 2011, p. 528). In 2013 in Finland, males (23 per cent) used slightly more often Internet telephony and video conferencing than females (19 per cent). The usage is also clearly more uncommon among 45 year-olds and older than among younger people (Statistics Finland, 2013). Also high level of education, young age and students are connected to use of Internet telephony and video calls in Finland (Statistics Finland, 2012, p. 32).

Three other measures are used to investigate asynchronous modes of communication. Social network sites (SNSs), such as Facebook and Twitter, have been defined as web-based services that allow people to build a public or semi-public profile within an enclosed system, to manage whom they share a connection with, and to view and crisscross their connections as well as those made by others (boyd \& Ellison, 2007). In Baron’s study (2008, p. 88) targeted at college students, women outpace men in being more frequent Facebook users and spending more time per day on the Internet. Hargittai’s study (2007, pp. 286-289), which surveys American college students, and the study by Vasalou, Joinson and Courvoisier (2010, p. 722), which is based on data collected from Facebook users from five countries, both reveal the higher likelihood of women being SNS users when compared with men. In Finland, women were more frequent users than men of SNSs in all age brackets in 2012. Women also considered themselves as more active agents on social networking sites than men (Statistics Finland, 2012, pp. 19-20).

The second asynchronous form of Internet use investigated here is blogs. The term blog emerged from 'web logs' as the blogging gained more visibility. Blogs are regularly modified web pages, which include various types of data entry in reverse chronological sequences (Herring, Scheidt, Wright, \& Bonus, 2005). In 2003, at the time when blogs were only just gaining popularity, Herring et al. (2005, p. 150) found that a slight majority of blog authors were young adult males. According to Statistics Finland (2012, p. 33), women read 
blog postings (42 per cent) more typically than men (34 per cent) in Finland. It seems that with the rise of fashion, beauty, decoration and mummy blogs, the sphere of blogs has become feminized. Furthermore, official statistics from Finland show that reading activity also decreases with age, and most active blog readers live in the capital region. Students and highly educated people are amongst the most active blog readers in Finland (Statistics Finland, 2012).

The third asynchronous form of Internet use considered in this study is online discussion forums (ODFs). These forums are based on asynchronous text-based communication (blogs include also pictures, videos, etc.), which make possible records of written messages without loss of data (Yang, Li, Tan, \& Teo, 2007, p. 572). ODFs represent the oldest form of social functionalities of the web analysed in this study. Yang et al. (2007) write that there were already many research projects on the use of ODFs, especially within student populations, carried out in the 1990s. Herring's (2003) study also documents that women-focused groups, where women were able to share experiences, began to proliferate as early as at the turn of the 1990s. Burr and Smith (2003), in their study of the users of a university’s ODF in Australia, indicate smaller gender and age differences. Women students were actually better represented in online discussion forums than men, and the use of online discussion forums increased rather than decreased with the age of the student. While there is no solid up-to-date statistical evidence on the popularity of ODFs in Finland, the most relevant data in this respect considers messages written and posted on the Internet (excluding emails). These figures, produced by Statistics Finland (2012, p. 32), reveals virtually no gender or educational differences. However, under 35 year-olds, students and people living in a capital region are more active message composers than others in Finland.

Lastly, it is in place to stress the vividness of the relationship between generations and digital social media. In today’s technology intensive world, the adoption and ways of using 
new technologies determine increasingly our generational consciousness. We become members of a generation by using technologies and media that are typical for it (Buckingham, 2006). However, digital technologies regenerate themselves at an accelerating pace, and younger generations especially easily change to newer technologies and applications. This is not only because of their technological progressiveness, but also because of their social need to find places of interaction that are beyond the reach of parental monitoring. The Internet provides for contemporary children and adolescents an arena where they can perform socially and nurture peer relations. In the past, these activities were practised in the public spaces of a town or city, which nowadays are often considered too unsafe for young people by their parents (boyd, 2014) In contrast, some other studies suggest that young people also share more and more new technology and digital content with their parents and grandparents (Baron, 2008, p. 233). Hence, it is clear that new digital and social technologies provide tools to enhance intrafamily communication and intergenerational solidarity (e.g. Dolničar, Hrast, Vehovar, \& Petrovčič, 2013; Lam, 2013; Wajkman, Bittman, \& Brown, 2008), and in this process a transitional 1DG may play a key role as they are more familiar with both old and new media than the 2DG, which is increasingly digital-only. Having said all this, it is obvious that generations are in a constant process of 'doing a generation' rather than in a passive state of ‘being a generation' (cf. 'doing a gender' on Butler, 1990; also Fortunati et al., forthcoming). In this process, a generation specific new technology may lose its determining role surprisingly quickly, and become replaced with a new technology, application or practice of use. In terms of analytical strategies, this implies that it is essential to study various social uses of the Internet separately, yet side by side. Bunching all these uses together and treating them as 'one social media' would prevent mode detailed understanding of generational differences in the social uses of the Internet. 


\section{Hypotheses}

Based on the above reviewed literate and considerations, the following hypotheses are defined for the study next.

Hypothesis 1 (H1): 2DG is more likely to use the social functions of the Internet than 1DG.

Hypothesis 2 (H2): 2DG is more likely to use the social functions of the Internet than DI.

Hypothesis 3 (H3): Except for high level of education, socio-demographic variables are not strongly associated with social uses of the Internet.

\section{Methodology}

Data

The data $(\mathrm{N}=612$ ) was collected from Finland during May-June 2011. The mode of data collection was a structured postal survey. The nationally representative sampling was carried out by the Population Register Centre of Finland. The sampling frame consisted of 15-65 year old Finnish speaking citizens covering all geographical regions of the country. The survey was pre-tested with ten persons. The response rate of the survey was 24 . The characteristics of the unweighted data are presented in Table 1. In all analyses, weighted data are used to correct skewed gender and age distributions which result from the higher nonresponse rate of 25-34 year old men and 35-44 year old women when compared with other groups.

The design of the questionnaire benefitted from two earlier survey studies. A majority of questions was adopted from the 'Telecommunication and Society in Europe' telephone survey that was carried out in Italy, Spain, Germany, France and the United Kingdom in 2009. This survey is a partial replica of another survey conducted in the same countries in 
1996 (Fortunati \& Manganelli, 1998). Both were developed by a group of distinguished scholars and funded by Telecom Italia. Another survey exploited was 'On the Move: The Role of Cellular Communications in American Life', which was conducted at the Department of Communication Studies at the University of Michigan in 2005 by Mike Traugott, Thomas Wheeler and Richard Ling (University of Michigan, 2006).

-- Insert Table 1 about here --

\section{Measurement instruments}

\section{Dependent variables}

Regarding the social use of the Internet, the following item from the questionnaire was employed: 'When using the Internet from home, which of the following activities do you practise at least sometimes?' The question was followed by a list of 25 activities, of which the following five are analysed in the present study: 'Use Messenger or other instant messaging service’; 'Make/receive calls with Skype or similar application’; ‘ Visit social networking sites (such as Facebook or MySpace)'; Visit blog sites'; and 'Take part in online discussion forums'. The supplied answering choices were 'Yes' and 'No'.

\section{Independent variables}

Generations were defined by asking for the year of birth, which was then recoded into full years $(M=44.45, \mathrm{SD}=15.07$, Range $=15-74)$ and further into three categories guided by previous research: digital immigrants (DI) (born before 1980); the first digital generation (1DG) (born between 1980 and 1989); and the second digital generation (2DG) (born 1990 or later). To measure gender, fixed answering categories, 'Male’ and 'Female’, were supplied. 
Education level was measured as the highest completed level of education in accordance with The International Standard Classification of Education (ISCED 97). The ISCED scale was recoded in three new categories to ensure the sufficient number of cases in each category: ‘Low education’ (ISCED levels 1 and 2), ‘Medium education’ (ISCED levels 3, 4 and 5b), and 'High education' (ISCED levels 5a and 6). The indicator for main activity was recoded from the question 'What describes your current situation best?' with the answers 'Employee', 'Housewife/-husband', 'Unemployed’, 'Pensioner', 'Student’ or ‘Other’. Measurement for children was developed from a question with ten fixed answering categories measuring the type of household. With recoding categories, a dummy variable with 'No children’ and 'Children (one or more)' categories was produced. It is worth noting that children are not inevitably the respondent's own, but belong to the same household. Household income was measured by asking 'What is the total annual income of your household? That is, the approximate total of all salaries, pensions and other revenues.' Answering categories ranging from 'Less than 20,000 Euros' to 'More than 80,000 Euros' were supplied ( $M=4.32$, SD = 2.32, Range $=1-8$ ). Lastly, the degree of urbanization of a respondent's place of abode was ascertained by asking 'How many inhabitants has your city/town/village?' and by providing eight answering categories. The answering categories were reduced to three, as outlined by the OECD: essentially rural (less than 5000 inhabitants), relatively rural (5001-100,000 inhabitants) and essentially urban (more than 100,000 inhabitants).

\section{Statistical methods}

The data was analysed by using both bivariate and multivariate statistical tools.

Distributions of dependent variables were analysed and presented by using contingency tables, chi-squared tests and standardized residuals. Logistic regression analyses (LRA) were conducted with an entered model, where the five social functionalities of the Internet worked as dependent variables. The Hosmer-Lemeshow test was used to indicate the goodness-of-fit 
of the LRA model. To identify the overall proportion of the variance explained by the model, Nagelkerke statistics were referred to (Tabachnick \& Fidell, 2007, pp. 459-461).

Furthermore, the total percentages of correctly predicted cases were analysed to assess the predicting capacity of the model.

\section{Results}

This section starts by looking at how common it is for different generations to use the social functionalities of the Internet. Table 2 presents distributions of five uses by generations without controlling any other factors. It shows that 2DG is the most engaged in all the studied activities, with the exception of visiting blogs. Blog reading is the most common practice among 1DG. With regard to instant messaging, social networking sites and online discussion forums, 1DG holds the second place. DIs really seem to be the least involved in social uses of the Internet, yet regarding Internet calls, the differences between three generations are not statistically significant.

-- Insert Table 2 about here -

The main results of this study are presented in Table 3, which summarises the outputs of five logistic regression models. Four out of five regression models explain between 17.9 and 29.0 per cent of the total variance. Only the model for Internet calls obtained a lower Nagelkerke's pseudo $\mathrm{R}^{2}$, which was 9.9. As a response to H1, which maintained that 2DG is more likely to use the social functionalities of the Internet than 1DG, the models reveal that it is only the synchronous forms of communication that make this difference. The youngest Internet users are more active using instant messages and Internet calls, both of which require simultaneous availability of the people engaged in the communication act. Instead, the analysis does not reveal statistically significant differences between 1DG and 2DG regarding 
the asynchronous forms of online communication. Both digital generations are actually relatively active on social networking sites, blogging and using online discussion forums. Given these results, $\mathrm{H} 1$ must be rejected.

-- Insert Table 3 about here --

The second hypothesis, H2, presents that 2DG is more likely to use the social functionalities of the Internet than digital immigrants. The results of this study do not provide solid support for this hypothesis either. From Table 3, it appears that DIs are not perhaps so categorically different from 2DG than is commonly believed when a range of other sociodemographic factors is controlled. It is true that DIs are less often engaged with the synchronous modes of communication and social networking sites than the newest generation of digital natives. Nonetheless, concerning the use of blogs and online discussion forums, the regression models are not able to confirm the statistical significance of generational differences (although the coefficients are relatively low).

Table 3 also provides many noteworthy results in respect to H3, which assumed that with the exception of high educational level, socio-demographic variables are not strongly associated with the social uses of the Internet. First of all, it can be noticed that the level of education is only related to the higher levels of Internet calls and discussion forum usage. These practices of Internet use, especially among older users, serve professional and more functional purposes (e.g. Cecere \& Corrocher, 2011; Constantiou \& Kautz, 2008) while the rest of the studied practices of Internet use_-instant messaging, social networking sites, blog use-are more utilized for non-professional purposes, and for this reason are not related to educational achievements either. 
Table 3 also points out that the three forms of asynchronous online communication are clearly gendered in nature. On the one hand, women more commonly use social networking sites and blogs than men. On the other hand, men are more often engaged with online discussion forums than women. These results resonate well with previous results showing that women use media technologies, such as telephone and the Internet, primarily for social purposes (e.g. to stay in touch with family and friends, to socialize), while male usage is more instrumental by nature (Kennedy, Wellman, \& Klement, 2003; Smoreda \& Licoppe, 2000). It is equally interesting to note that the studied forms of synchronous online communication do not reflect any gender differences. Regarding socio-demographic variables other than gender, Table 3 shows that respondents living in the most urban locations and those living in a household with low overall income are more likely to utilize instant messaging than others. It might be that the urban living environment with lots of impulses especially feeds the use of instant messaging, which, of the study's forms of Internet use, is most clearly premised on the idea of instant, simple and even facile communication.

\section{Discussion and concluding remarks}

Synchronicity in communication really matters when studying differences between digital generations. This conclusion can be drawn from the present study, which shows that synchronous social uses of the Internet are clearly generationally differentiated practices in Finland, while asynchronous social uses of the Internet are not. In particular, the second digital generation (2DG) of Finns favours those modes of communication that are based on real-time and synchronized interaction with others.

This main finding can be further elaborated upon and discussed in the light of two concepts: privacy and communicative efficiency. The higher involvement of 2DG in synchronous communication can be considered as an indication of their preference for 
communication modes that are more similar to face-to-face interaction than asynchronous means of communication (e.g. ODF, blogs or, above all, emails). Instant messaging and social networking sites especially provide users with private (and semi-private) channels of interaction and mingling with peers, which are activities that older generations were able to perform more freely face-to-face in shopping centres, at street corners or other public spaces. Today, these places are considered less safe, which leads to a relative social isolation and disempowerment of contemporary children and teenagers. At the same time, it must be noted that the investigated synchronous modes of Internet use particularly preferred by 2DG are predominantly private means and targeted at one-to-one communication. In contrast, blogs and ODFs are more aimed at one-to-many communication, which means making communication more public. The increased interest in synchronous modes of communication among the youngest generation can thus also be regarded as an expression of their will not to publicize all their vocalized expressions (also, boyd, 2014, p. 57). For the youngest generation, the social uses of the Internet present themselves first and foremost as a way to be with peers and friends, not to be in public.

Additionally, the greater willingness to use synchronous modes of online communication among 2DGs can be elaborated in relation to the notion of communicative efficiency. Taipale (2014) writes that, in Finland, college students highlight the importance of typing with a keyboard loads of text and quickly. They also aim to finish the text at once, without returning to the same text later ('one-off writing'). Such quick and instant production of text is expected to result in the efficient use of time. Similarly, synchronous modes of communication, whether written (e.g. instant messaging) or oral (e.g. Internet telephones), that are based in real-time communication and instant responses, contribute to the same ultimate goal of high communicative efficiency. Against this backdrop, it is tempting to suggest that increasingly popular synchronous forms of digital communication may give rise 
to a new temporality that is especially shaped by 1DG and its particularly strong desire for immediate and efficient, yet also more private forms of communication. Considering recent qualitative studies from other countries that have elaborated young people’s intense engagement with real-time communication tools and debunked the myth of digital generations as publicity-seeking teenagers (e.g. boyd, 2014) it may well be that the results presented here are not limited to just Finland. Furthermore, the present study illustrates that the dividing line between 1DG and 2DG is neither clear cut nor unequivocal. The mere greater immersion in social media is not enough to adequately understand the differences between 1DG and 2DG. The results support more the view that distinguishing factors between consecutive digital generations are more specific and subtle when it comes to digital technologies and applications, and that these factors are closely related to the particular needs and values of each generation (e.g. need for privacy). In the absence of proper longitudinal and in-depth data, it is still tempting to propose that 2DG seems to be actively 'doing' its generation by engaging itself actively in synchronous communication, and in this way making a distinction from previous generations who are more accustomed to older and asynchronous modes of online communication. Nevertheless, there are also reasons for arguing that asynchronous forms of communication are not vanishing from daily communications. Even if people are increasingly equipped with mobile communication devices which allow them to be always on and available, we cannot avoid asynchronicity in social life. First of all, much online context and communications is persistent, meant to be stored and to be rediscovered later (boyd, 2014, pp. 11, 27). Furthermore, synchronous modes of communication are not always even a true choice. Even if family solidarity and peer relations require the mutual synchronization of schedules (Wajkman, Bittman, \& Brown, 2008), the organic solidarity of the modern world (Durkheim, 1984) implies structural temporal asymmetries, both within and between societies (e.g. shift work and time zones), 
which are hard or impossible to circumvent. In certain situations, these asymmetries make real-time communication impossible and people have to turn to asynchronous modes of communication whether they want to or not. It seems that 2DG is somewhat less affected by these temporal asymmetries than 1DG and DI, who have considerably more work and family related responsibilities. This implies that the success of synchronous modes of communication among DG2 is also partially accounted for the generation's current stage of life. The use of a/synchronous communication tools may be subject to change as this generation grows up, enters the labour market, and begins to marry and have children of their own. Some concluding remarks can be made on the limitations of the study and future research directions. Over the course of the study, it was seen how precious it would be to have longitudinal data that would enable comparisons over time. In future, it would of great importance to study how the generational differences in the a/synchronous modes of communication discovered here evolve over time, and whether or not older generations will begin to use more synchronous modes of Internet-based communication in the future. Another limitation and future research need relates to motivations behind the synchronous and asynchronous usage of the Internet. Not only should motivation and reason to use be modelled statistically, but in-depth qualitative research is also needed to describe the meanings that the youngest digital generation ascribe to synchronous communication and to understand how this meaning-making influences their generational consciousness. Similarly, the meaning of mobility in synchronous and asynchronous communication deserves more scholarly attention, as mobile devices have truly detached the use of Internet-based communication, both synchronous and asynchronous, from homes and other stationary locations. 


\section{References}

Baron, N. S. (2008). Always on: Language in an online and mobile world. New York: Oxford University Press.

boyd, d. (2014). It's complicated: The social lives of networked teens. New Haven, London: Yale University Press.

boyd, d. d., \& Ellison, N. B. (2007). Social network sites: Definition, history, and scholarship. Journal of Computer-Mediated Communication, 13, 210-230. doi: 10.1111/j.1083-6101.2007.00393.x

Buckingham, D. (2006). Is there a digital generation? In D. Buckingham \& R. Willett (Eds.), Digital generations: Children, young people and new media (pp. 1-13). Mahwah, NJ: Erlbaum.

Burr, L., \& Smith, L. (2003). The digital divide: an urban miss? In G. Crisp, D. Thiele, I. Scholten, S. Barker \& J. Baron (Eds.), Interact, integrate, impact: Proceedings of the 20th annual conference of the Australasian society for computers in learning in tertiary education (pp. 95-103). Adelaide, 7-10 December 2003.

Butler, J. (1990). Gender trouble: Feminism and the subversion of identity. London: Routledge.

Cecere, G., \& Corrocher, N. (2011). The intensity of VoIp usage in Great Britain: Users’ characteristics and firms’ strategies. Telecommunications Policy, 35, 522-531. doi:10.1016/j.telpol.2011.04.004

Constantiou, I. D., \& Kautz, K. (2008). Economic factors and diffusion of IP telephony: Empirical evidence from an advanced market. Telecommunications Policy, 32, 197211. doi:10.1016/j.telpol.2007.07.010

Davies, C., Coleman, J., \& Livingstone, S. (Eds.) (2014). Digital technologies in the lives of young people. London: Routledge 
Dingli, A., \& Seychell, D. (2015). The new digital natives: Cutting the chord. Berlin: Springer.

Dolničar, V., Hrast, M. F.,Vehovar, V., \& Petrovčič, A. (2013). Digital inequality and intergenerational solidarity: The role of social support in proxy internet use. Selected Papers of Internet Research (SPIR). Retrieved from http://spir.aoir.org/index.php/ spir/article/viewFile/734/324

Durkheim, E. (1984). The division of labor in society. Basingstoke: Macmillan.

Fortunati, L., \& Manganelli, A.M. (1998). La comunicazione tecnologica: Comportamenti, opinioni ed emozioni degli Europei [Technological communication behaviour, opinions and emotions in Europe] (pp. 125-194). In L. Fortunati (Ed.), Telecomunicando in Europa [Telecommunication in Europe]. Milan: Angeli.

Fortunati, L., Taipale, S., \& de Luca, F. (forthcoming) Digital generations, but not as we know them.

Fuchs, C. (2008). Internet and society: Social theory in the information age. New York: Routledge.

Fuchs, C. (2010). Web 2.0, prosumption, and surveillance. Surveillance \& Society, 8. Hargittai, E. (2007). Whose space? Differences among users and non-users of social network sites. Journal of Computer-Mediated Communication, 13, 276-297. doi: 10.1111/j.1083-6101.2007.00396.x

Hargittai, E. (2010) Digital na(t)ives? Variation in internet skills and uses among members of the “"net generation". Sociological Inquiry, 80, 92-113. doi: 10.1111/j.1475682X.2009.00317.x

Helsper, E. J. (2010). Gendered internet use across generations and life stages. Communications Research, 37, 352-374. doi: 10.1177/0093650209356439 
Helsper, E. J., \& Eynon, R. (2010). Digital natives: Where is the evidence? British Educational Research Journal, 36, 503-520. doi: 10.1080/01411920902989227

Herring, S. C. (2003). Gender and power in online communication. In J. Holmes \& M. Meyerhoff (Eds.), The Handbook of Language and Gender. Malden: Blackwell, pp. $202-228$.

Herring, S. C., Scheidt, L. A., Wright, E., \& Bonus, S. (2005). Weblogs as a bridging genre. Information, Technology \& People, 18, 142-171. doi: 10.1108/09593840510601513

Herring, S. (2008). Questioning the generational divide: Technological exoticism and adult constructions of online youth identity. In D. Buckingham (Ed.), Youth, identity, and digital media (71-92). Cambridge, MA: The MIT Press.

Kennedy, T., Wellman, B., \& Klement, K. (2003). Gendering the digital divide. IT \& Society, $1,149-172$.

Lam, S. S. K. (2013). ICT's impact on family solidarity and upward mobility in translocal China. Asian Journal of Communication, 23, 322-340.

Lee, L. (2008). The impacts of young people's internet use on class boundaries and life trajectories. Sociology, 42, 137-153. doi: 10.1177/0038038507084829

Montgomery, K. C. (2007). Generation digital: Politics, commerce, and childhood in the age of the internet. Cambridge, MA: The MIT Press.

Park, N. (2010). Adoption and use of computer-based voice over internet protocol phone service: Toward an integrated model. Journal of Communication, 60, 40-72. doi: 10.1111/j.1460-2466.2009.01440.x

Pilcher, J. (1994). Mannheim’s sociology of generations. British Journal of Sociology, 45, 481-495.

Prensky, M. (2001a). Digital natives, digital immigrants. On the Horizon, 9(5), 1-6.

Prensky, M. (2001b). Digital natives, digital immigrants, part 2. On the Horizon, 9(6), 1-6. 
Prensky, M. (2009). H. sapiens digital: From digital immigrants and digital natives to digital wisdom. Innovate, 5.

Smoreda, Z., \& Licoppe; C. (2000). Gender-specific use of the domestic telephone. Social Psychology Quarterly, 63, 238-252.

Statistics Finland (2012). Tieto- ja viestintätekniikan käyttö 2012 [Use of information and communications technology in 2012]. Helsinki: Statistics Finland.

Statistics Finland (2013). Use of information and communications technology by individuals in 2013. Retrieved from http://www.stat.fi/til/sutivi/2013/sutivi_2013_2013-11$\underline{07 \text { tau_011_fi.html }}$

Statistics Finland (2014). Väestön tieto- ja viestintätekniikan käyttö 2014 [Use of information and communications technology in 2014]. Retrieved from http://www.stat.fi/til/sutivi/2014/sutivi_2014_2014-11-06_fi.pdf

Tabachnick, B. G., \& Fidell, L. S. (2007). Using multivariate statistics. 5th ed. Boston, MA: Pearson.

Taipale, S. (2014). The affordances of reading/writing on paper and digitally in Finland. Telematics and Informatics, 32, 532-542. doi: 10.1016/j.tele.2013.11.003

Tapscott, D. (1998). Growing up digital: The rise of the net generation. New York: McGraw Hill.

University of Michigan (2006). On the move: The role of cellular communications in American life. Pohs report on mobile communication. Ann Arbor: University of Michigan

Vasalou, A., Joinson, A. N., \& Courvoisier, D. (2010). Cultural differences, experience with social networks and the nature of "true commitment" in Facebook. International Journal of Human-Computer Studies, 68, 719-728. 
Wajkman, J., Bittman, M., \& Brown, J. (2008) Families without borders: Mobile phones, connectedness and work-home divisions. Sociology, 42, 635-652.

Wellman, B., Quan Haase, A., Witte, J., \& Hampton, K. (2001). Does the Internet increase, decrease, or supplement social capital? Social networks, participation, and community commitment. American Behavioral Scientist, 3, 436-455.

Yang, X., Li, Y., Tan, C.-H., \& Teo, H.-H. (2007). Students' participation intention in an online discussion forum: why is computer-mediated interaction attractive? Information \& Management, 44, 456-466. 